\title{
LOS ADJETIVOS LATINOS RELACIONADOS CON ACERBVS. SIGNIFICADO ORIGINAL Y DERIVACIONES METAFÓRICAS *
}

\author{
CONCEPCIÓN FERNÁNDEZ MARTÍNEZ \\ Universidad de Sevilla \\ cfernandez@us.es
}

En este artículo se ofrece una interpretación de los adjetivos relacionados con acerbus, en los textos literarios y en las inscripciones métricas (en las que adquieren un sentido especializado en relación con la mors immatura) con arreglo a la Teoría Contemporánea de la Metáfora y según la metodología ya ensayada en un trabajo anterior de la misma autora sobre acerbus. El estudio de estos adjetivos permite proponer una traducción satisfactoria de los mismos en los textos literarios y epigráficos.

Palabras clave: Latín; Literatura; Epigrafía; Metáfora; Semántica.
In this paper the author offers an interpretation of the adjectives related to acerbus, in literary texts and metrical inscriptions (where a specialized meaning for premature death is found), according to the Metaphor Contemporary Theory (MTC) and following the methodology tested in a previous paper of the same author for acerbus. This study allows us to propose a satisfactory interpretation and translation of the adjectives, in both literary and epigraphic texts.

Key words: Latin, Literature, Epigraphy, Metaphor, Semantic

\section{INTRODUCCIÓN.}

En un trabajo anterior y recientemente publicado en EMERITA ${ }^{1}$, estudiaba de un modo sistemático el significado del adjetivo latino acerbus, no siempre entendido e interpretado con exactitud; de tal modo que unas veces parecía significar 'amargo', otras 'punzante', o 'doloroso', e incluso, en no pocas ocasiones, 'prematuro'.

Por lo que respecta a los significados - literal y metafóricos - del adjetivo en cuestión, y como ya quedó demostrado en el citado trabajo, la Teoría

Este trabajo se ha realizado dentro del proyecto BFF2000-0398 de la DGICYT del MEC, titulado "Poesía Epigráfica Latina en Hispania: edición y comentario". La autora pertenece a un Grupo de Investigación financiado por la Junta de Andalucía, dentro del P.A.I. (cód. HUM 0156).

1 «Acerbus: la amargura de morir antes de tiempo», EMERITA 71,2, 2003, pp. 313-337; citado en adelante como Fernández 2003). 
Contemporánea de la Metáfora (TCM), ofrecía, en el caso del acerbus latino - como en tantas otras palabras de cualquier lengua ${ }^{2}$ - nuevas vías para la comprensión de su significado exacto.

En efecto, el adjetivo, procedente, como quedaba demostrado, de una realidad tangible y cercana a nuestra experiencia ('los frutos inmaduros son amargos'), facilitó la comprensión de otras dos realidades no tan concretas ni fáciles de entender: la amargura del alma (y entonces significaba 'doloroso') y la duración de la vida del hombre (y entonces significaba 'prematuro'). De manera que el campo semántico de acerbus se fue configurando en torno a una u otra de estas dos derivaciones metafóricas.

\section{PUNTO DE PARTIDA.}

A la vista de que los distintos usos - epigráficos y literarios - del adjetivo acerbus nos confirmaban el acierto de las nuevas teorías sobre la metáfora, y convertían además al adjetivo en cuestión en un ejemplo más, muy ilustrativo, de los mecanismos conceptuales capaces de generar las múltiples derivaciones metafóricas conocidas en todas las lenguas, parece oportuno completar esta línea de investigación con el estudio de algunos adjetivos de significado similar o idéntico al de acerbus y sobre los que hayan podido operarse, tanto en los textos literarios como en los epigráficos en verso, los mismos tipos de derivaciones metafóricas. Me refiero a casos como praematurus, properatus, immitis, immaturus, crudus, crudelis, amarus, acer, acidus, asper, durus, rigidus, etc. El estudio de ellos constituye el objetivo fundamental de estas páginas.

\section{METODOLOGÍA Y TIPOS.}

Como vimos en el trabajo citado, el adjetivo acerbus, desde su significado originario y concreto (el amargor de los frutos inmaduros) y a través de dos derivaciones metafóricas bien diferenciadas, había entrado en relación con dos espacios conceptuales distintos: por una parte, con la reacción de amargura interna que provocan en nosotros las situaciones adversas y hostiles, y, por otra, con el discurrir temporal de la vida humana, cuando ésta se trunca antes de tiempo, sin que llegue a 'madurar'. De tal forma que acerbus puede compartir uno de sus espacios significativos con otros adjetivos que

2 Cf., por ejemplo, Lakoff \& Jonson 1980, donde se encuentran ejemplos ilustrativos. EMERITA (EM) LXXIV 1, enero-junio 2006 pp. 113-144 ISSN 0013-6662 
tengan que ver con la 'anticipación' o, en definitiva, con cualquier hecho sucedido antes de tiempo, y otro con aquellos adjetivos que, partiendo de un significado concreto, relacionado con la inmadurez de un fruto (por amargor, acidez, dureza o incluso 'falta de cocción', como veremos infra), hayan desarrollado una -o ambas- de las derivaciones metafóricas conocidas y demostradas para acerbus.

Dividiremos, pues, los adjetivos sometidos a estudio en los siguientes grupos:

A. Aquellos cuyo significado originario hace referencia a cualquier sensación concreta relacionada con los frutos inmaduros (sabor, tacto, etc.) y puedan emplearse, en principio, además de con su significado concreto, con las dos derivaciones metafóricas conocidas para acerbus: la de la amargura del alma o la adversidad y la de la mors immatura). Revisaremos en este primer grupo los siguientes adjetivos: immitis, amarus, acer, acidus, asper, crudus, crudelis, durus, rigidus.

B. Aquellos que hacen referencia al paso del tiempo en relación con la madurez de los frutos (immaturus, praematurus, properatus ${ }^{3}$ ) y que pueden, por tanto, emplearse en contextos de mors immatura.

\section{EL CORPVS.}

\section{Grupo A.}

\subsection{IMMITIS.}

\subsubsection{El diccionario.}

El recorrido por los distintos diccionarios ${ }^{4}$ nos explica el origen de immitis como una forma compuesta por el preverbio privativo in y el adjetivo mitis. Presentaría, pues, un significado literal, opuesto a mitis ('dulce', aplicado en general al sabor y en particular a los frutos, al que se le une una idea de 'maduro' y 'tierno'), que bien podría ser, por tanto, 'inmaduro', 'verde', 'áspero al gusto, etc. y que se aplica sobre todo (como en el caso del adjetivo simple) a los frutos (a la uva en Hor., C. II 5.10) y a los vinos. Tendría además un significado metafórico en relación con la percepción sensorial (como también lo tenía acerbus en los autores literarios), llegando a

3 Si bien este último nunca se aplicó a la inmadurez de los frutos, como veremos en la descripción de su significado y en sus usos tanto literarios como epigráficos.

4 Hemos consultado, como hicimos para el caso de acerbus, los siguientes: el diccionario etimológico de Ernout y Meillet, el Thesaurus Linguae Latinae, el de R. de Miguel, el de F. Gaffiot, el OLD (ed. Glare) y la versión electrónica del de Lewis \& Short.

EMERITA (EM) LXXIV 1, enero-junio 2006 pp. 113-144 ISSN 0013-6662 
significar 'cruel', 'inhumano', 'severo' 5 , etc., funcionando, pues, como sinónimo de adjetivos como barbarus, toruus, immanis, ferox, crudelis o saeuus. Para ambos tipos de significado, el literal y el metafórico, se nos ofrecen ejemplos literarios en prosa y en verso.

Como se ve, ninguno de los diccionarios menciona la posibilidad de que immitis haya dado lugar a una derivación metafórica relacionada con la duración de la vida del hombre, ni su consecuente significado de 'prematuro', que sí tenía acerbus, aunque de modo incipiente, en la literatura, y, en exclusiva, en la poesía epigráfica.

\subsubsection{La literatura.}

Su búsqueda en los autores literarios ${ }^{6}$ nos ofrece, sin embargo, resultados interesantes:

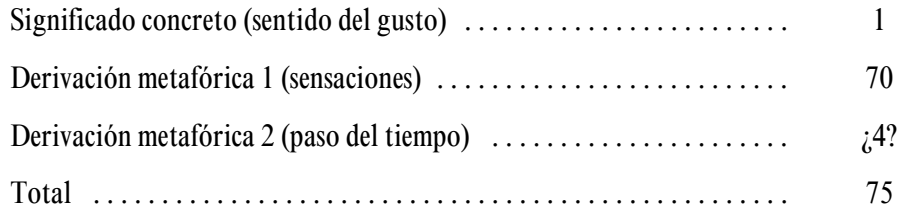

En primer lugar, y mirando el número total de ocurrencias en los poetas seleccionados, vemos de entrada un uso considerablemente inferior de este adjetivo, en comparación con su 'sinónimo' acerbus (75 frente a 104). Por lo que respecta a su significado literal, podemos abundar en una de las conclusiones a que llegábamos en el estudio de acerbus: también immitis perdió casi del todo su significado originario y literal que hacía referencia al 'sabor amargo o ácido que produce una reacción de aspereza en la lengua'.Y en el caso de immitis esta pérdida podría decirse que es más acusada (sólo uno de los 75 textos conserva su significado originario), si bien el número de ejemplos puede no ser lo suficientemente elevado como para poder extraer conclusiones más definitivas. También aquí, fue este significado tan concreto y palpable el que facilitó el uso 'metafórico' del adjetivo dentro de otros campos significativos menos concretos, más difíciles de aprehender y que necesitaban, por tanto, recurrir a algún concepto mejor estructurado y más fácilmente inteligible. Desde

5 También mitis se usaba con frecuencia como sinónimo de placidus, tranquillus, lenis, etc. (v. Ernout-Meillet, s. v.)

6 Seleccionamos también aquí los mismos poetas cuyos textos habíamos rastreado en el caso de acerbus, es decir, aquellos que compartieron, de un modo evidente y demostrable, un universo común de referencias culturales con los autores, las más de las veces 'desconocidos', de poesía epigráfica (a saber: Plauto, Lucrecio, Catulo, Virgilio, Horacio, Tibulo, Propercio, Ovidio, Marcial, Apuleyo, Silio Itálico y Estacio). Se excluyen de los respectivos cuadros sinópticos los autores que no presenten ocurrencias del adjetivo en cuestión.

EMERITA (EM) LXXIV 1, enero-junio 2006 pp. 113-144 ISSN 0013-6662 
una realidad concreta como es la amargura del fruto inmaduro, se pueden llegar a entender, al menos parcialmente, las sensaciones - nada concretas - de amargura, enemistad, crueldad, etc.; pues producen en nuestro interior una reacción similar a la que experimenta nuestra lengua al probar un fruto inmaduro. A este respecto, resulta especialmente ilustrativo de los mecanismos mentales capaces de generar este tipo de derivaciones metafóricas, un ejemplo de Virgilio en el que se establece una contraposición entre una dulce comida y unos nidos crueles, amargos, despiadados (Georg. IV 17: ore ferunt dulcem nidis immitibus escam); significado mayoritario del adjetivo, que incluso con frecuencia se coordina a (o se pone en relación con) adjetivos como saeuus, cruentus, inuidus o ferus: Tib. I 3.48: Inmiti saeuus duxerat arte faber; III 4.74: Inmitem dominam coniugiumque ferum; Stat., Theb. XII 184: segreget, inmitesque deos regemque cruentum; Silu. II 3.38: immitem Bromium, stagna inuida et inuida tela, etc.

En relación con la segunda de las derivaciones metafóricas con que se utilizó acerbus, la situación es considerablemente distinta en el uso de immitis. Si bien 25 de los 104 textos literarios con acerbus, desarrollaban un significado metafórico relacionado con el paso del tiempo en la vida del hombre (si un fruto caído o arrancado prematuramente resulta acerbus o immitis, también la muerte acaecida antes de tiempo será acerba o immitis), ahora los textos en los que podemos descubrir esta segunda acepción se reducen a $4^{7}$, entre los cuales cabe destacar un texto de Tibulo ${ }^{8}$, concretamente en su autoepitafio literario: Tib. I 3.55: Hic iacet inmiti consumptus morte Tibullus, referido a una hipotética mors immatura. Un hexámetro que no tuvo la fortuna de aquel otro virgiliano (Aen. VI 429: abstulit atra dies et funere mersit acer$b o$ ), que contribuyó al éxito y expansión de este uso de acerbus en la literatura y en la epigrafía, sin duda por la mucha menor difusión de un poeta como Tibulo ${ }^{9}$.

En definitiva, podemos concluir que también para immitis, y en mayor medida que para acerbus, prevalece la primera de las acepciones en la literatura.

\subsubsection{La epigrafía.}

Una vez más, como así ocurría en el caso de acerbus, es precisamente la derivación metafórica menos usual en los autores de poesía 'conocidos' (apenas un ejemplo seguro y tres dudosos que recurren al símil frutal frente a los 70 que establecían una relación conceptual con el plano de la percepción sensorial), la única que acti-

$7 \quad$ Cat. LXIV 245; Prop. IV 11.13; Stat., Silu. III 3.193.

8 De dudosa interpretación son los casos de Ov., Nux 69, Cat. LXIV 245, Prop. IV 11.13, Stat., Theb. VII 774, y Silu. III 3.70.

9 De hecho, por ejemplo, Bücheler y Lommatzsch señalan en su índice de pasajes de Virgilio citados o recordados en los CLE un total de 360 casos de correspondencias, mientras que en el caso de Tibulo estas correspondencias se reducen a 24 .

EMERITA (EM) LXXIV 1, enero-junio 2006 pp. 113-144 ISSN 0013-6662 
van los autores "desconocidos" de poesía epigráfica. Y es esta uniformidad la que nos permitiría hablar, también para immitis, de una especialización epigráfica del adjetivo. Sólo que, curiosamente, immitis es un adjetivo de uso escasísimo en la poesía epigráfica: tres únicos ejemplos, uno de los cuales está en un texto corrupto, de forma que quedan en realidad reducidos a $\operatorname{dos}^{10}$ (CLE 1057,4: E[leuthe] ris haeret et puer, inmites que[em rapuere]... y 2125,2: consumpta inmiti morte sepulta iacet); ambos referidos claramente a una mors immatura y que, en todo caso y con todas las cautelas a que nos obliga ese reducidísimo número de ejemplos, confirman nuestra hipótesis de especialización epigráfica. Las razones para tal especialización en este caso (además de que en uno de los textos podemos llegar a reconocer ecos inequívocos del autoepitafio de Tibulo: CLE 2125,2: consumpta inmiti morte sepulta iacet, adaptado al ritmo del pentámetro), podrían estar en la similitud de ambos adjetivos, acerbus e immitis, que comparten, en la literatura y en la epigrafía, el mismo significado literal y las mismas derivaciones metafóricas.

\subsection{AMARVS.}

\subsubsection{El diccionario.}

El adjetivo amarus tiene el significado básico de 'amargo al gusto', por oposición a dulcis y es definido por Lewis \& Short (en su versión electrónica) como sinónimo de acerbus. A partir de este significado inicial, puede desplazarse hacia el sentido del oído y aplicarse de hecho a sonidos penetrantes y agudos (Stat., Theb. 553); o hacia el sentido del olfato, llegando a expresar olores desagradables (Plan. I 12.30: fructus amarus odore). Desde esa amargura concreta asociada a los sentidos del gusto, oído u olfato, el adjetivo pudo establecer relaciones conceptuales con sensaciones igualmente desagradables o amargas que afecten a otros sentidos ya no tan concretos; de ahí el significado metafórico, frecuente en la literatura, como veremos, de 'amargo, triste, desagradable, molesto, irritable', etc., que puede calificar tanto a personas como a hechos, palabras, etc.

\subsubsection{La literatura.}

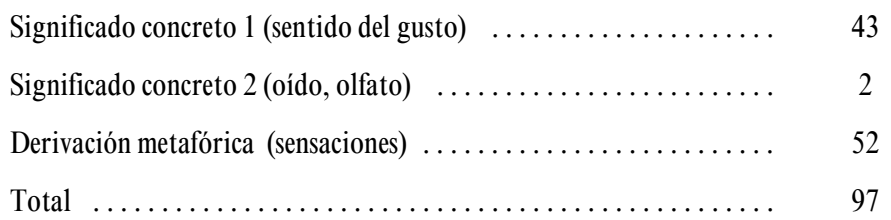

Amarus, adjetivo de significado concreto asociado fundamentalmente, como hemos visto, al sentido del gusto, pertenece al mismo grupo que acerbus e immitis. De

10 Frente a los 61 que hallábamos de acerbus.

EMERITA (EM) LXXIV 1, enero-junio 2006 pp. 113-144 ISSN 0013-6662 
uso ligeramente inferior al primero y superior al segundo (97 ejemplos frente a 104 y 75 , respectivamente), presenta ya a simple vista una notable diferencia con respecto a ambos: la gran abundancia de usos con su acepción más literal y concreta, referida a los sentidos del gusto o del oído; un total de 45 ejemplos que casi alcanzan la mitad del total, entre los que destacamos, a modo de muestra: Pl., Cas. 223: fel quod amarumst, id mel faciet, hominem ex triste lepidum et lenem; Verg., Ecl. VI 68: floribus atque apio crinis ornatos amaro; Georg. II 314: infelix superat foliis oleaster amaris; Ov., Her. XX 184: fert aliis tristem sucus amarus opem.

En el estudio que habíamos hecho sobre sus sinónimos acerbus ${ }^{11}$ e immitis nos llamaba la atención la pérdida casi absoluta de su significado originario y literal que hacía referencia al sabor amargo de los frutos inmaduros; este significado literal era el que facilitaba la derivación metafórica de los adjetivos hacia otros campos significativos menos concretos, de tal modo que ambos dejaron de usarse con su significado básico, para lo cual, naturalmente, habría que echar mano de otros adjetivos sinónimos; uno de los cuales, como nos muestran los textos de los autores seleccionados, fue sin duda amarus.

La otra mitad son usos metafóricos relacionados con otras sensaciones de amargura o crueldad, mucho menos concretas. Así: Verg., Aen. 10.591: quem pius Aeneas dictis adfatur amaris; Hor., S. I 7.7: confidens, tumidus, adeo sermonis amari, etc., sin que tal adjetivo, a diferencia de los restantes que venimos estudiando, se asocie - salvo muy excepcionalmente ${ }^{12}$ - a contextos de muerte.

\subsubsection{La epigrafía.}

Usado tan sólo en dos ocasiones, por lo que no podemos ser nada concluyentes en nuestros comentarios, amarus ha desarrollado en la poesía epigráfica la misma derivación metafórica que en los textos literarios, sin que se pueda relacionar de modo directo con contextos de mors immatura: 1554,5: lacrimis meorum amaris (donde se llora la muerte de una mujer de 39 años, en un poema sin ningún tópico de los usados en casos de mors immatura) y 186,5: numquam inter nos fecimus uerbum amarum.

Da la impresión, pues, de que precisamente por el hecho de conservar en los autores literarios su significado literal (para suplir la ausencia de acerbus o immitis en esos mismos contextos), se ha alejado más de sus usos metafóricos, hasta el punto de que, por una parte, amarus apenas sí se ha usado en la poesía epigráfica, y, por otra, no ha llegado a desplazarse, como sus sinónimos, hasta llegar a asumir el significado de 'prematuro' o 'anticipado', en contextos de mors immatura.

11 Cf. Fernández 2003.

12 Sólo un ejemplo: Prop. I 19.20: tum mihi non ullo mors sit amara loco.

EMERITA (EM) LXXIV 1, enero-junio 2006 pp. 113-144 ISSN 0013-6662 


\subsection{ACIDVS.}

\subsubsection{El diccionario.}

Adjetivo formado a partir de la raíz ac- (al igual que acerbus y acer), desde un significado básico y etimológico relacionado con lo 'agudo' o 'penetrante' (cf. Ernout-Meillet s.v.) ha sido aplicado en primer lugar al sentido del gusto (sapor) y desde éste al del oído, para calificar un sonido de 'penetrante' o 'chirriante'. Una derivación metafórica ulterior ha facilitado, en ocasiones y a través de unas relaciones conceptuales fácilmente explicables (desde lo concreto hacia lo abstracto), su uso para situaciones desagradables, amargas o dañinas, como muestran algunos de los ejemplos del párrafo siguiente.

\subsubsection{La literatura.}

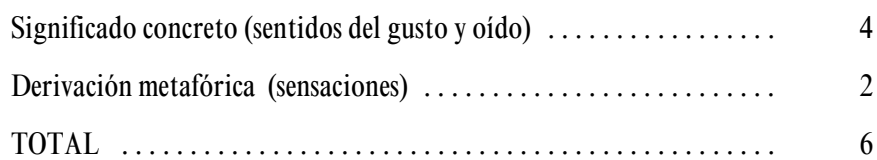

Su uso en los autores seleccionados resulta, como vemos, tan escaso que no nos permite extraer conclusiones fiables. Obsérvese, no obstante, cómo el número de usos concretos (del tipo Verg., Georg. III 380: fermento atque acidis imitantur uitea sorbis) supera (en el doble, si bien estos números deben manejarse con gran cautela) al de sus derivaciones metafóricas hacia el ámbito de las sensaciones hirientes o acuciantes (Hor., Ep. II 2.64: quod petis, id sane est inuisum acidumque duobus).

\subsubsection{La epigrafía.}

Si escaso era el número de ejemplos en los autores literarios, nulo es su uso en la poesía epigráfica. En este caso, puesto que el significado del adjetivo no se relaciona etimológicamente con el paso, más o menos rápido, del tiempo, ni su más concreta 'acidez' parece haberse empleado de un modo especializado para los frutos inmaduros (no es así, de hecho, en ninguno de los ejemplos de los autores seleccionados), no es de extrañar su ausencia en los contextos de mors immatura que venimos revisando.

\subsection{ACER.}

\subsubsection{El diccionario.}

Igualmente formado a partir de la raíz ac-(como acerbus y acidus) ${ }^{13}$, desde su significado básico y etimológico relacionado con lo 'agudo' o 'penetrante' (cf.

13 Para los problemas que plantea la cantidad de la $\bar{a}$ de $\bar{a} c e r$, cf. Ernout-Meillet s.v.

EMERITA (EM) LXXIV 1, enero-junio 2006 pp. 113-144 ISSN 0013-6662 
Ernout-Meillet s.v.) ha sido aplicado a cualquiera de los sentidos: vista (Lucr. IV 304), oído (Verg., Georg. IV 409), olor (Lucr. VI 1217), y, naturalmente, sabor (Hor., S. II 8.7: dulcibus cibis acres acutosque miscere); en ese mismo sentido, concreto y tangible, sirvió también para calificar al dolor físico (Lucr. VI 658-59: arripit acer saepe dolor dentes), e incluso, al borde mismo ya de la metáfora, al frío (Hor., C. I 4.1: soluitur acris hiems) o al calor (Lucr. VI 850-51: et acri sole puant subter terras feruescere partim). Y a partir de estos significados concretos y gracias a una derivación metafórica (desde el dolor del cuerpo al dolor del alma, por ejemplo) según los mecanismos que venimos describiendo a lo largo de estas páginas, ha podido emplearse para situaciones, personas o sensaciones (en general dolorosas, desagradables, crueles o hirientes) mucho más abstractas. De ahí esos significados (de los que da cuenta el cuadro siguiente) de 'violento', 'fiero'o, en definitiva, 'acuciante'.

\subsubsection{La literatura.}

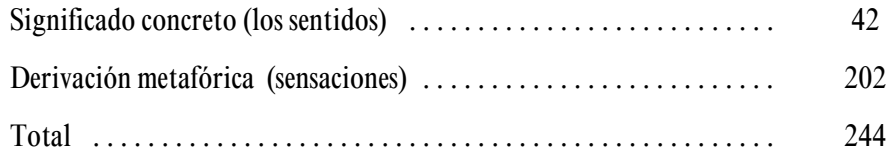

Con este recuento de ejemplos, el adjetivo acer se convierte en uno de los más usados de la serie que estudiamos (si exceptuamos el caso especial de durus que cuenta, como veremos infra, con 617 ocurrencias). Cabe destacar sobre todo la extensión mayoritaria de su acepción metafórica relacionada con la fiereza, la enemistad o la amargura, pues 202 de los 244 se reparten entre ejemplos como: Pl., Bacch. 628: multa mala mi in pectore nunc acria atque acerba eueniunt (obsérvese en este ejemplo su coordinación con acerba); Lucr. V 399: at pater omnipotens ira tum percitus acri; Verg., Aen. III 682: praecipitis metus acer agit quocumque rudentis; Tib. II 6.15: acer Amor, fractas utinam, tua tela, sagittas; Ov., Met. III 540: nunc sinitis sine Marte capi? uosne, acrior aetas, etc. No debemos pasar de largo, por otra parte, el hecho de que muy pocos de esos significados 'concretos' se relacionen con el sentido del gusto y que en ninguno de ellos sirva para calificar el sabor de los frutos que no han madurado, encontrándose más bien junto a alimentos 'agrios' o 'podridos' (cf., por ejemplo, Lucr. IV 637: ut quod aliis cibus est aliis fuat acre uenenum; Hor., S. II 4.59: potorem coclea; nam lactuca innatat acri); de ahí que no haya tenido un ámbito de aplicación en contextos de mors inmatura ni en la literatura ni en la epigrafía, como veremos.

\subsubsection{La epigrafía.}

Frente al uso abundante de este adjetivo entre los poetas seleccionados, llama la atención el hecho de que acer sólo se emplee tres veces en los CLE (569,2: [inque 
acr]es luctus conuertit uota parentum; 488,2: acri homini adque alacri forti fido...; 629,2: inde regrediens incidi febribus acris); todos ellos, como puede comprobarse, con su acepción metafórica y sin que lleguen a formar parte (salvo en el primer ejemplo, que no es más que una reconstrucción) de contextos de mors immatura. Es indudable que este adjetivo debió de sufrir la competencia de otros similares, tanto para la derivación metafórica de la crueldad, acritud o dolor acuciante, como para la que podría haberlo relacionado - desde el amargor de los frutos - con la mors immatura.

\subsection{ASPER.}

\subsubsection{El diccionario.}

Adjetivo con un significado originario muy concreto y referido al sentido del tacto, se usó en primer lugar para expresar algo desagradable al tacto; de ahí los significados frecuentes de 'rugoso, rocoso, áspero', etc. Se le conocen también otras acepciones, no menos concretas, relacionadas con los sentidos del gusto (con el significado de 'amargo' o, en definitiva, 'desagradable'), del oído (con el significado de 'áspero' o 'chillón') e incluso del olfato, para olores que resultan penetrantes (cf., por ejemplo, Ernout-Meillet, OLD, Lewis \& Short, s.v.). Desde estos significados concretos de desagrado, ha desarrollado también, como otros adjetivos similares que venimos estudiando, una derivación metafórica relacionada con sensaciones abstractas de violencia, fiereza, amargura, dureza o adversidad, como vemos en un buen número de textos de los poetas seleccionados.

\subsubsection{La literatura.}

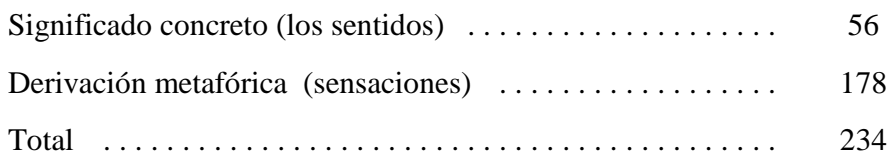

Su frecuencia de uso es similar a la de acer, si bien se documenta un cierto incremento en el número de ejemplos con sus más concretos significados originarios. Entre ellos, destacan muy especialmente los textos referidos a cualquier tipo de aspereza al tacto (así, Verg., Ecl. III 89: mella fluant illi, ferat et rubís asper amomum; Ov., Her. 9.112: aspera texerunt uellera molle latus; Ov., Fast. 2.348: horrebant densis aspera crura pilis y otros muchos ejemplos similares); aunque no faltan algunos aplicados al sentido del gusto y referidos a alimentos amargos (aunque en ninguno de los casos se usa para los frutos inmaduros), con una acepción muy cercana a la de amarus, hasta el punto de aparecer ambos adjetivos coordinados (Lucr. II 404: at contra quae amara atque aspera cumque uidentur, Verg., Georg. IV 277: asper in ore sapor, entre otros). Algunos de los ejemplos nos dejan ver con facilidad los mecanismos conceptuales que hicieron posible el desplazamiento de este adjetivo hacia

EMERITA (EM) LXXIV 1, enero-junio 2006 pp. 113-144 ISSN 0013-6662 
las sensaciones nada concretas ya de desagrado o 'exasperación' (quizá la traducción más adecuada para esta acepción metafórica); es así como en Verg., Georg. IV 245: aut asper crabro imparibus se immiscuit armis, nos encontramos con un abejorro áspero al tacto y capaz al mismo tiempo de proporcionarnos desagradables sensaciones, transmitiéndonos en definitiva una conceptual blending ${ }^{14}$, es decir, un espacio mental que incorpora elementos procedentes de variadas fuentes; similar interpretación podrían tener los casos en que asper se aplica al mar a la vez 'encrespado' y 'fiero' (Ov., Met. XV 720: asper enim iam pontus erat). Finalmente, la mayor parte de ejemplos expresan ya, en exclusiva, la derivación metafórica de la fiereza, lo desapacible, la exasperación (así en: Verg., Aen. 2.96: promisi ultorem et uerbis odia aspera moui; Hor., Ep. II 1.7: dum terras hominumque colunt genus aspera bella; Sil. Ital., Pun. 4.597: impulit asper equus fessumque sub aequora mersit,etc.).

\subsubsection{La epigrafía.}

Reducidísimo resulta el uso epigráfico de asper frente al literario; cuatro ejemplos, uno sólo de los cuales (CLE1365,7: iam dudum castum castigans aspera corpus delituit uestis) conserva el significado originario de la aspereza al tacto, mostrando los otros tres la conocida derivación metafórica $(1,4 ; 546,1$ y 1189,7). Como vemos, su significado concreto en relación con el sentido del tacto, si bien en ocasiones ha podido aplicarse a algunos alimentos, no ha llegado nunca a usarse para la sensación de 'aspereza' que producen los frutos inmaduros; de ahí que no se haya desplazado, metafóricamente, hasta contextos de mors immatura, como sí lo hicieron acerbus o immitis.

\subsection{CRVDVS.}

\subsubsection{El diccionario.}

El adjetivo crudus, relacionado etimológicamente con cruor y crudelis, tiene el significado básico de 'sangrante'. De ahí que, además de aplicarse, en sentido propio, a las heridas (cf. Lewis \& Short, s. v.), se haya aplicado también, desde el principio, a los alimentos 'crudos', 'sin cocinar'. Desde este sentido de 'inacabado' se ha extendido igualmente a los frutos 'verdes' y a todo lo inacabado o inmaduro. Los distintos diccionarios nos muestran además un uso 'poético' con el sentido de 'cruel', 'amargo', que ha podido sobrevenirle desde su originario significado de 'sangrante' (con uulnera en Ov., Tr. III 11.19), o bien a partir de su frecuente uso para los frutos verdes, por los mismos caminos conceptuales descritos ya para casos como el de acerbus o immitis.

14 Se trata de la conocida conceptual blending o fusión conceptual de dos o más campos significativos (que citábamos en nuestro trabajo sobre acerbus); cf. al respecto Lakoff 1991, pp. 11-12; Grady, Oakley \& Coulson 1999, pp. 101-124 y Fauconnier \& Turner 1994.

EMERITA (EM) LXXIV 1, enero-junio 2006 pp. 113-144 ISSN 0013-6662 


\title{
1.6.2. La literatura.
}

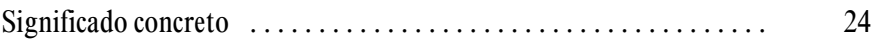 \\ Derivación metafórica 1 (sensaciones) $\ldots \ldots \ldots \ldots \ldots \ldots \ldots \ldots \ldots$ \\ Derivación metafórica 2 (paso del tiempo) $\ldots \ldots \ldots \ldots \ldots \ldots \ldots . \quad 14$ \\ Total ......................................... 75
}

Asciende, como vemos, el número de casos de este adjetivo, hasta igualarse, por ejemplo, con immitis. Llama la atención, en comparación con los restantes adjetivos, el hecho de que conserve con mucha frecuencia, en los autores literarios (otra cosa será, como veremos, su uso en poesía epigráfica), su significado originario de 'sangrante' o 'crudo'; precisamente el que le ha facilitado su aplicación a los frutos inmaduros, valor a partir del cual, ha podido dar lugar a las mismas dos derivaciones metafóricas, trasladando, por un lado, la aspereza del fruto inmaduro al campo de la percepción sensorial ${ }^{15}$ (y éste es su uso mayoritario, como puede apreciarse en el cuadro), y utilizándolo en relación con cualquier hecho que aún no ha llegado a su término (en sólo 14 ejemplos ${ }^{16}$ ).

\subsubsection{La epigrafía.}

Este adjetivo está muy escasamente representado en la poesía epigráfica: sólo dos ejemplos (lo que nos tiene que llevar a valorar con cautela las posibles conclusiones), 526,7: set crudum indignumque nefas et triste... y 1355,6: soror trieteride quinta Taenareas crudo funere uidit aquas; en ambos se trata de casos de mors immatura, sin que aparezca, por tanto, con los otros dos significados con que se documenta en los textos literarios. Su comportamiento, en definitiva, es muy comparable al de acerbus o immitis estudiados supra.

\subsection{CRVDELIS.}

\subsubsection{El diccionario.}

Formado a partir de crudus y relacionado, por tanto, etimológicamente con cruor, los distintos diccionarios recogen, sin embargo, un uso bastante regular y unitario de este adjetivo, que parece tener el único significado de 'cruel' o 'salvaje', bien aplicado a las personas, bien a las acciones o sucesos. El adjetivo tomaría, pues - en exclusiva, según parece deducirse de los distintos diccionarios -, uno de los significados derivados que había desarrollado crudus. Así, tanto en prosa como en

15 Así en: Ov., Am. III 8.58: seruiat, hi pacem crudaque bella gerant; Her. IX 67: non tibi succurrit crudi Diomedis imago; Sil. Ital., Pun. VII 113: crudum Marte uiri nomen, etc.

16 Todos en la línea de: Sil. Ital., Pun. III 303: Baniurae cruda iuuentus; Stat., Theb. IV 280: cruda puerperio; Stat., Ach. I 478: cruda rudimento et teneros formauerit annos.

EMERITA (EM) LXXIV 1, enero-junio 2006 pp. 113-144 ISSN 0013-6662 
poesía se comportaría como sinónimo de ferox (cf. Lewis \& Short, s.v.), immitis, durus, ferus, saeuus (cf. Raimundo de Miguel, s.v.); suele aparecer, además, coordinado o relacionado con adjetivos como superbus, tyrannus, taeter o acerbus. Sus usos literarios, sin embargo, nos muestran, como comprobaremos en la tabla siguiente, algunas variaciones de interés respecto a lo recogido en los diccionarios.

\subsubsection{La literatura.}

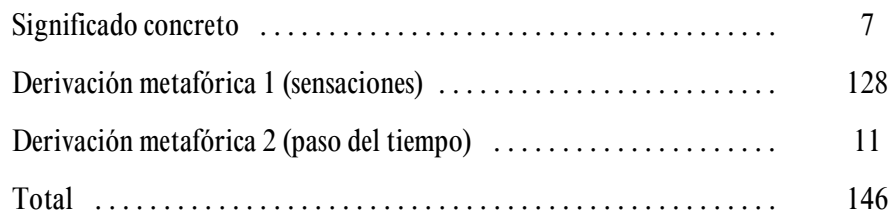

Adjetivo muy usado, presenta un significado regular y mayoritario (128 de 146) - pero no único - relacionado con la crueldad; el mismo que uno de los que había desarrollado crudus a partir de su aplicación a los frutos verdes, cuyo sabor resulta desagradable. Pero, además de esta acepción, que es la única que recogen los diccionarios, crudelis ha conservado su sentido etimológico de 'sangrante' (el mismo que tenía también crudus) en un pequeño grupo de ejemplos de Virgilio (4 casos) y Ovidio (3 casos); así, por ejemplo, en: Ov., Met. XIII 531: quid moror interea crudelia uulnera lymphis; Fast. V 469: saeue Celer, crudelem animam per uolnera reddas; Verg., Aen. I 355: crudelis aras traiectaque pectora ferro. Pero sobre todo (y de esto tampoco se hacen eco los diccionarios) resultan especialmente interesantes los ejemplos en que Virgilio (en 9 ocasiones ${ }^{17}$ ) y Marcial (en $2^{18}$ ), usan este adjetivo con la acepción de 'prematuro' (derivación metafórica que también conocía crudus a partir de su extensión a los frutos verdes y a todo lo inmaduro o inacabado, como veíamos supra); y lo hacen curiosamente en contextos de mors immatura. Así, Verg., Ecl. V 20: exstinctum Nymphae crudeli funere Daphnin; Georg. III 263: nec moritura super crudeli funere uirgo, etc; sintagma éste repetido no sólo en distintos versos virgilianos sino en muchos de los poemas epigráficos, como veremos infra. Esta última acepción, casi desconocida en la literatura e ignorada por los diccionarios al uso, será, en efecto, la que prevalecerá en la poesía epigráfica.

\subsubsection{La epigrafía.}

Llama la atención, en primer lugar, el amplio uso que de este adjetivo se hace en la poesía epigráfica, 68 ejemplos; un número sólo comparable a los 70 casos de

\footnotetext{
17 Además de los dos citados: Ecl. V 23, Aen. I 221, IV 308, X 386, XI 53, XI 841 y XII 636.

18 XXIV 18.5 y VI 62.3.
}

EMERITA (EM) LXXIV 1, enero-junio 2006 pp. 113-144 ISSN 0013-6662 
acerbus e infinitamente superior al de los restantes adjetivos estudiados en este trabajo. Pero las acepciones y los contextos en que encontramos este adjetivo, distan mucho de los hallados en los autores literarios examinados; en efecto, la acepción de 'crueldad' o 'amargura del alma' que encontrábamos de modo mayoritario y casi único en la poesía de autores conocidos - y que era la única que registraban los diccionarios -, ahora queda reducida a 6 ejemplos, 4 de ellos, además, en contexto de mors immatura $(1212,5 ; 702,5 ; 702,9 ; 1971,6)$; otro aplicado como epíteto al dios de los infiernos (971,8: crudelis Pluton, nimio saeuite rapinae) y sólo uno sin relación alguna con la muerte (307,1: Eutychius martyr crudelia iussa tyranni). Además, y como también habíamos detectado en algunos poetas conocidos (Virgilio, Ovidio y Estacio), en un pequeño grupo de poemas epigráficos el adjetivo recupera su valor etimológico de 'sangrante', para ser aplicado, por ejemplo -como vimos que lo era crudus-, a las heridas; se trata de un par de ejemplos que se mantienen, no obstante, dentro de un contexto de mors immatura, de tal manera que hablan de 'heridas sangrantes precisamente por ser prematuras ${ }^{19}(1612,18$ : dolebunt crudeli mortis meae uulnere y 1639,1: amissum mater crudeli uolnere natum). Pero son los 60 ejemplos restantes los que resultan especialmente interesantes, al utilizarse sistemáticamente en contextos claros de mors immatura, combinados con las expresiones más usuales para este tópico (verbos como rapio, propero, en epitafios de padres a hijos, mencionando a las Parcas que rompen sus hilos antes de tiempo, etc.: 1281,1: una dies adimit crudeli clade peremtas; 1143,2: compleras nubilis Nahum Vibia, crudeli funere rapta uiro; 1026,1: Itala me rapuit crudeli funere tellus; 493,8: dura peregistis crudelia pensa sorores); o en sintagmas muy similares a los que se usaban con el adjetivo acerbus (cuyo significado de 'inmaduro' o 'prematuro' había quedado demostrado en el trabajo citado al comienzo de estas páginas); e incluso en combinación con él (1591,8: matris eripuerunt immeritum Parcae crudeles funere acerbo; 971,5: uerbis maledicere acerbo. crudele pater funus nati uidisse uideris ; y llegando a recordar el conocido verso virgiliano que tanto contribuyó a la extensión del sintagma funus acerbum ${ }^{20}$ (588,6: funere mersit, suiusque reuersum crudeli funere corpus; 1011,1: inuida mors rapuit fato crudelis iniquo). Es interesante a este respecto, recordar el importante papel de Virgilio como difusor, aunque no necesariamente iniciador, de determinados versos, hemistiquios o sintagmas, en esa 'civilización epigráfica' en la que convivieron poetas reconocidos y autores anónimos de poesía epigráfica.

Podríamos, pues, hablar, a la vista de los resultados, de un uso especializado de crudelis en los $C L E$, para los casos de mors immatura, tal y como habíamos visto y demostrado para el adjetivo acerbus. Una especialización semántica en la que preci-

19 Se trata de la conocida conceptual blending mencionada supra.

20 Verg., Aen. VI 429 y XI 28: abstulit atra dies et funere mersit acerbo. Cf. además Fernández 2003, pp. 313-337, esp. 322-323.

EMERITA (EM) LXXIV 1, enero-junio 2006 pp. 113-144 ISSN 0013-6662 
samente acerbus ha podido jugar un papel importante, al entenderse, en cierta medida y en este contexto concreto de mors immatura, como sinónimo de crudelis, tras haber sufrido ambos el mismo proceso de derivación metafórica a partir de su aplicación a los frutos que aún no han madurado. No olvidemos que poetas como Virgilio, Marcial o Estacio habían hecho uso también de esta misma acepción -como vimos supra-, lo que nos confirma nuestra idea, desarrollada en el citado trabajo sobre acerbus, de ese universo cultural que compartieron, como fuente de inspiración, los autores epigráficos y los literarios.

Esta especialización de que hablamos no deja de tener una cierta importancia, por variados motivos. En primer lugar, porque, como en el caso de acerbus, nos confirma igualmente el acierto de las nuevas teorías de la metáfora (la tendencia natural a recurrir a una realidad concreta e inmediata para tratar de explicar otra mucho más abstracta y difícil de entender); pero sobre todo por la clarificación e incluso ampliación de las acepciones tradicionalmente admitidas para este adjetivo, con todo lo que ello supone a la hora de interpretar y traducir los textos epigráficos en los que se inserta. Nos ayuda además a distinguir definitivamente lo que significa crudelis en la literatura latina en general y en la poesía epigráfica en particular. Por último, el conocimiento exhaustivo del significado de este adjetivo en las inscripciones en verso puede, en algún caso, proporcionarnos claves para la interpretación de textos oscuros; es el caso precisamente del verso 8 del carmen 1515, procedente de Ammaedara: iam te non Tartara crudelem tenebunt; un texto difícil en el que Bücheler corrige crudelem en crudele, para poder entenderlo como un adverbio; mientras que el editor del CIL prefiere leer crudelia, para asignárselo a Tartara, una corrección sin fundamento, que convertiría este endecasílabo mal compuesto (y ya con 12 sílabas) en uno igualmente mal compuesto y de trece sílabas. Ninguna de estas correcciones se hace necesaria tras nuestro conocimiento de que crudelis tiene en poesía epigráfica un uso especializado para la mors immatura, que lo convierte en sinónimo de acerbus, de tal modo que el texto africano, sin sufrir correcciones ${ }^{21}$, podría interpretarse de la siguiente manera: "no te retendrá antes de tiempo el Tártaro" 22.

\subsection{DVRVS.}

\subsubsection{El diccionario.}

Adjetivo sin ninguna etimología segura (cf. Ernout \& Meillet, s.v.), fue puesto

21 Llamo la atención sobre el carácter "provisional” de esta interpretación, puesto que, por el momento, no he podido hacer la autopsia de la inscripción y ni siquiera observar una foto de ella. Sólo su lectura sobre el soporte podría darnos la solución e interpretación definitivas.

22 Para más detalles sobre la interpretación de este verso cf. C. Fernández Martínez, «Iam te non Tartara crudelem tenebunt (CLE 1515,8)», en curso de publicación en Exemplaria Classica, 2 (2005).

EMERITA (EM) LXXIV 1, enero-junio 2006 pp. 113-144 ISSN 0013-6662 
en relación con *druros, reconstruido a partir del sánscr. darunah ('rudo, fuerte'),

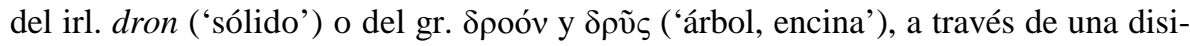
milación sin precedentes y poco verosímil.

El Thesaurus Linguae Latinae (s.v.), después de relacionarlo con el gr. sklerós y stereós y de oponerlo a mollis y a facile penetrabilis, menciona su primer ámbito de aplicación (de corporeis) y su relación inicial con el sentido del tacto (pertinet ad tactum). Asimismo, y en relación también con el sentido del tacto, se describe cómo han podido ser calificados como durus la tierra, los árboles, las hierbas, las plantas o los alimentos; e incluso los frutos, a los que les confiere el significado opuesto a bene in arbore maturata. En segundo lugar durus puede afectar también al sentido del gusto, y así se aplica a los alimentos o al vino, con el significado opuesto a suauis. Se describe después un uso no ya propio sino derivado, que redefine el adjetivo como difficilis perpessu, toleratu uel factu; y en este sentido sirvió para calificar algunas desgracias, injusticias, mandatos, palabras, etc., hasta llegar a igualarse con adjetivos como intractabilis, obduratus e incluso con crudelis o immitis.

Raimundo de Miguel (s.v.), sin embargo, establecía una relación etimológica con douron ('leño') y definía durus como 'duro, sólido, cruel, áspero, rígido, rudo, dificultoso, adverso, etc.'; además señalaba también su aplicación a los alimentos o al vino, cuyo mejor ejemplo tal vez sea el sintagma durum acetum (Seren., Med. 3.37). Finalmente, completa una ilustrativa lista de sinónimos que nos ayuda a perfilar bien su significado: solidus, firmus, grauis, ponderosus, acer, laboriosus, difficilis, arduus, calamitosus, aduersus, noxius, asper, molestus, rudis, impolitus, saeuus, immitis, rigidus.

Gaffiot (s.v.) da como primer significado 'duro al tacto' y como segundo 'áspero al gusto'; y desde ahí pasa a una serie de acepciones menos concretas, relacionadas con el esfuerzo, la crueldad, la dificultad, etc.

El Oxford Latin Dictionary (s.v.) enumera las siguientes acepciones: en primer lugar 'referente al tacto, duro, sólido'; con una segunda acepción se aplica al sentido del gusto, pasando a significar 'fuerte', por lo que sirve para calificar los distintos alimentos, sabores, bebidas, etc. Por último, y en sentido figurado, puede aplicarse al ámbito de la percepción sensorial, con el significado de 'duro, implacable, severo, difícil,', etc. Una descripción paralela -aunque menos completa- que la que recibe este mismo adjetivo en el ThLL.

Lewis \& Short (s.v., en su versión electrónica) son quienes nos proporcionan - como también ocurría en el caso de acerbus - una descripción quizá más acertada. Para empezar, nos ofrecen una serie de palabras latinas con definiciones similares (algunas de las cuales coinciden con las que leíamos en Raimundo de Miguel): acer-

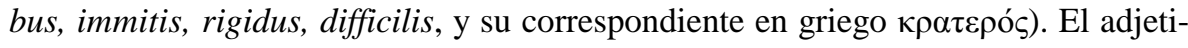
vo se define directamente como 'duro' (hard). Después, detallan su significado ori- 
ginal y concreto en relación con el sentido del tacto, por lo que se aplicó desde el principio a las rocas, piedras, armas de hierro, etc. Desde su primitiva relación con el sentido del tacto se ha desplazado hacia el sentido del gusto; por eso, y con el significado opuesto a suauis se ha aplicado al vino (Verg., Georg. IV 102) o al vinagre, como veíamos supra. Igualmente se ha desplazado también hasta el sentido del oído y se ha aplicado a los sonidos, las consonantes, las sílabas, etc. Tras los significados propios se enumeran los figurados, los transferidos, es decir, las derivaciones metafóricas; y es así como durus ha podido llegar a significar 'rudo, vigoroso, resistente, insensible, desagradable, adverso', etc., y aplicarse al frío, a las enfermedades, al hambre, a las costumbres, a las personas, etc.

\subsubsection{Comentario.}

Sea cual fuere su etimología, podemos deducir de este recorrido por los distintos diccionarios un primer significado concreto, relacionado con "la dureza al tacto". De nuevo aquí, como en el caso de acerbus, llama la atención el carácter excesivamente descriptivo de la mayor parte de los diccionarios, pues, junto a este primer significado, y sin establecer ninguna relación de parentesco, dependencia o derivación metafórica, se enumeran, como hemos visto, algunos otros, ya sea concretos (relacionados con el sentido del gusto o el oído), ya sea abstractos (aplicados a situaciones adversas, mandatos crueles, personas dañinas, etc.). Una vez más también, constituye una excepción parcial el tratamiento que recibe durus por parte de Lewis \& Short (en su versión electrónica), que, al menos, distinguen con claridad los usos literales de los transferidos, explican cómo pudo desplazarse un mismo significado concreto desde el sentido del tacto a los del gusto u oído, y cómo, por último, llegó a significar 'rudo', 'desagradable' o 'adverso', por derivación metafórica desde lo concreto y tangible a lo abstracto e intangible.

Dentro del estudio que venimos realizando y que ahora emprendemos para $d u$ rus, nos interesan muy especialmente algunos de estos usos. En primer lugar, el desplazamiento semántico que ha facilitado la acepción relacionada con la 'crueldad' que también tenía acerbus-, a través de unos mecanismos de derivación que - como bien explicaba la $\mathrm{TCM}^{23}$ - nos permiten conocer las relaciones conceptuales que rigen nuestro lenguaje y nos llevan a conceptualizar un dominio mental (sobre todo si éste es abstracto) en términos de otro (mucho más concreto). Pero nos interesan sobre todo aquellos casos en que el significado de durus se ha desplazado desde el ámbito del sentido del tacto al del gusto y se ha podido aplicar, por tanto, a los frutos que no han madurado en el árbol, al vino de sabor fuerte, al vinagre, etc. Un significado que lo ha convertido en sinónimo de acerbus y que puede haber facilitado - como veremos que ocurre en la poesía epigráfica - la misma derivación metafórica

23 Véanse las primeras páginas de Fernández 2003.

EMERITA (EM) LXXIV 1, enero-junio 2006 pp. 113-144 ISSN 0013-6662 
de aquél, hacia la vida truncada antes de tiempo y su consiguiente uso en los epitafios en verso que recrean el tópico de la mors immatura.

\subsubsection{La literatura.}

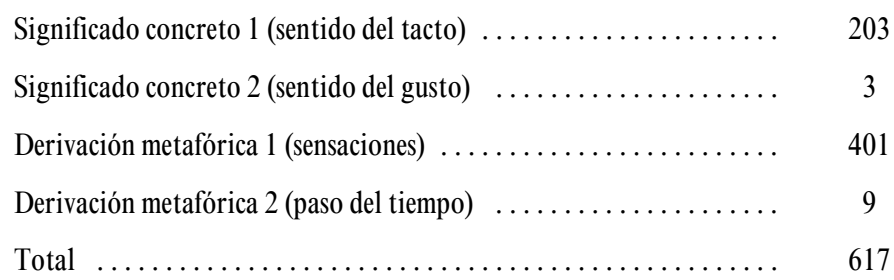

Sorprende en primer lugar - y en comparación con el resto de los adjetivos estudiados - la elevadísima frecuencia de uso de este adjetivo en la selección de poetas con la que trabajamos. Su primer significado concreto y etimológico, relacionado con la 'dureza al tacto' parece tener aquí una mayor fuerza que en el resto de los adjetivos estudiados, ya que es el que se conserva en un tercio de los casos (Lucr. V 1064: mollia ricta fremunt duros nudantia dentes; Verg., Ecl. IV 30: et durae quercus sudabunt roscida mella, etc.). Un número simbólico y poco representativo de ejemplos (concretamente tres) registra el desplazamiento de ese mismo significado concreto, desde el sentido del tacto al del gusto; así en Verg., Georg. IV 102: et liquida et durum Bacchi domitura saporem, en un fragmento en el que se enfrentan sabores dulces y fuertes; o en Ov., Met. VII 594: concipit et fundit durum inter cornua uinum, y sobre todo Fast. II 253: stabat adhuc duris ficus densissima pomis; ejemplo este último especialmente interesante, pues desde ese significado de dureza aplicado al sentido del gusto, vemos cómo se ha aplicado a los frutos inmaduros, identificándose con acerbus y facilitando, también en literatura, pero sobre todo -como veremos- en poesía epigráfica, la derivación metafórica que le ha conferido el significado de immaturus. Apenas un ejemplo registra el mismo significado de dureza aplicado al sentido del oído (Prop. II 33a.10: et pecoris duro perdere uerba sono) y la mayor parte de los casos (¡dos tercios del total!) desarrollaron de modo preferente una derivación metafórica del adjetivo desde la que pudo expresar situaciones desagradables, adversas, crueles, etc. Así, por ejemplo, en: Lucr. V 1272: nec poterant pariter durum sufferre laborem; Verg., Ecl. X 44: nunc insanus amor duri me Martis in armis). Pero una vez más, como en el caso de crudelis, es un pequeño grupo de ejemplos ( 9 en total, 5 de los cuales son de Virgilio) el que nos llama especialmente la atención, pues se usan con el significado de 'prematuro' y se asocian a contextos de muerte anticipada; el mismo significado que ya habíamos encontrado en crudus y crudelis, discretamente en la literatura y de modo especializado en la epigrafía (cf. supra). Un significado muy alejado, en apariencia, del valor originario y concreto de durus, pero que ha podido llegar a adquirir fácilmente a través de sus

EMERITA (EM) LXXIV 1, enero-junio 2006 pp. 113-144 ISSN 0013-6662 
usos relacionados con el sentido del gusto, que, como hemos visto, se aplicaban muy especialmente a los frutos aún no madurados. Valgan como ejemplos los siguientes: Verg., Aen. X 745: olli dura quies oculos et ferreus urget o Aen. X 791: hic mortis durae casum tuaque optima facta ${ }^{24}$.

\subsubsection{La epigrafía.}

Desciende el número de usos de durus con respecto a crudelis, pero su presencia en 43 poemas epigráficos sigue siendo considerable (el segundo en frecuencia de los que estudiamos) y nos permite extraer conclusiones fiables. Una vez más el uso epigráfico dista del literario a la hora de seleccionar sus distintas acepciones. Sin embargo, a diferencia de lo que venimos encontrando en el resto de los adjetivos, el significado literal, asociado a la dureza al tacto (que ya era importante en la literatura, pues alcanzaba a un tercio de los textos), se conserva también en la epigrafía y no de modo simbólico ni del todo excepcional, llegando a aparecer en 8 ejemplos como los que siguen: 1135.4: grata magis Terrae quam tibe, dure lapis y 965,2: incisum et duro nomine erit lapide. La derivación metafórica que lo ha llevado a expresar la crueldad, dureza o amargura del alma, que era el uso más abundante (dos tercios del total) en los autores literarios seleccionados, se reduce aquí a ocho textos, porque estos anónimos poetas epigráficos han preferido la derivación metafórica que, desde el significado concreto asociado a los frutos sin madurar, ha servido para enriquecer una vez más el tópico de la mors immatura (que alcanza a los 27 restantes). Unos ejemplos en los que se detecta la influencia de acerbus y que nos dejan ecos, directos o indirectos, del conocido verso virgiliano que tanto tuvo que ver en la especialización epigráfica de acerbus y algunos de sus sinónimos (Aen. 6.29 y 11.28: abstulit atra dies et funere mersit acerbo ${ }^{25}$ : 1406.1: dura quidem frangit paruorum morte parentes; 768.1: quem funere duro eu nimium celere rapuit mors impia; 545.1: Glycerium, fors abstulit funere duro, mersit in aeternam extincto corpore).

El uso epigráfico de durus nos muestra, en definitiva, una clara tendencia a la especialización de este adjetivo para los casos de mors immatura, como ya venimos viendo que sucede en no pocos de los adjetivos que estamos sometiendo a estudio. La especialización se ha operado aquí, como en otros casos similares, a partir de la aplicación de su significado concreto de dureza, al sentido del gusto, sirviendo,

24 Verg., Aen. VI 377, XII 309, Georg. III 68; Mart. IX 86.9; Stat., Theb. IX 664, Silu. III $1.172, \mathrm{~V} 1.178$.

25 Cf., además de Chevallier 1972, p. 59, Gómez Pallarès 1993, que en n. 21 explica cómo el verso virgiliano tiene su origen en expresiones epigráficas y sobre todo "en la utilización especializada que suele hacerse en los CLE del adjetivo acerbus" (p. 226); Ricci, Carletti y Gamberale 1983, p. 217-218; Fernández Martínez 1998-99, p. 54 y 2003, esp. pp. 329-333.

EMERITA (EM) LXXIV 1, enero-junio 2006 pp. 113-144 ISSN 0013-6662 
pues, para designar los frutos aún no madurados. Desde ahí, ya no resulta difícil imaginar las relaciones conceptuales que se han podido establecer entre durus, acerbus, immitis, etc., y que, en contextos relacionados con la muerte, han facilitado y extendido su uso metafórico para la vida humana que se trunca antes de tiempo.

Esta tendencia a la especialización de durus para los casos de mors immatura es paralela a la ya comentada de crudelis y nos permite extender aquellos comentarios y conclusiones, también al caso de durus (las referidas a la común fuente de inspiración de autores epigráficos y literarios, las que destacan el importante papel que debió jugar acerbus en la extensión de su acepción metafórica, y las que nos ayudan, en fin, a conocer de modo exhaustivo el significado de todos estos adjetivos y a interpretarlos, por tanto, en los textos epigráficos en que se insertan).

\subsection{RIGIDVS.}

\subsubsection{El diccionario.}

Adjetivo deverbativo, formado a partir de rigeo, tiene el significado de 'rígido', 'duro', usado con mucha frecuencia para expresar, como idea accesoria (cf. ErnoutMeillet, s.v. rigeo), el efecto del frío (rigida tellus: tierra helada), o para cualquier dureza o rigidez causada por tensión (rigida mentula). Desde cualquiera de estos significados concretos, por derivación metafórica relacionada con la dureza de los sentimientos, ha podido llegar a usarse con los significados de 'cruel, inflexible, fiero, severo', etc. Así se explica la diversidad de sinónimos que le asigna Raimundo de Miguel en su Diccionario: desde su significado concreto y originario aparecería como sinónimo de rigens, gelidus, stans, rectus, erectus, durus, inflexibilis, etc., y desde sus signifcados metafóricos resultaría intercambiable (además de con durus, por ejemplo) con inmitis, saeuus o crudelis.

\subsubsection{La literatura.}

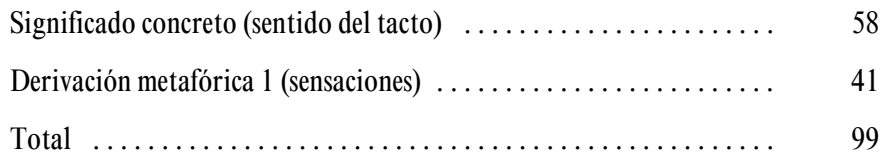

Los resultados, como puede observarse en el cuadro, son muy similares a los de amarus, tanto en la frecuencia de uso como en la distribución de sus dos únicas acepciones, la más concreta y originaria y la derivación metafórica, más abstracta, en relación con la dureza de los sentimientos o con el carácter más o menos severo o inflexible de las personas. Así, abundan por un lado los ejemplos como Verg., Georg. I 508: et curuae rigidum falces conflantur in ensem, Ov., Am. II 6.4: et rigido teneras unge notate genas, o aplicados a las aguas heladas, como Ov., Tr. Nec 
poterit rigidas findere remus aquas; y por otro los que califican a enemigos crueles, dioses inflexibles o fieros leones, como Hor., C. III 24.11: uiuunt et rigidi Getae, Ov., Met. VIII 20: spectare ex illa rigidi certamina Martis, o Mart. X 65.13: nec dorcas fugax rigido leoni.

\subsubsection{La epigrafía.}

El mismo paralelismo con amarus, en frecuencia y acepciones, advertido en los autores seleccionados, encontramos en la poesía epigráfica: de nuevo dos únicos ejemplos (tampoco en este caso podremos ser concluyentes), y ambos con la misma derivación metafórica que en los textos literarios, sin que en ninguno de ellos aparezca la menor relación con el tópico de la mors immatura: 704,8: scriptorum custos rigidus ('severo guardián de las escrituras') y 899,7: qui potuit rigidas Tothorum subiere mentes ('capaz de dominar el inflexible valor de los godos').

Parece confirmarse la hipótesis de que precisamente los adjetivos que de un modo mayoritario conservan en la literatura su significado más literal (en este caso la rigidez o dureza), desarrollan menos derivaciones metafóricas; es así como rigidus, además de su significado literal ampliamente documentado, ha servido también para expresar, metafóricamente, la dureza de los sentimientos, pero su significado de 'dureza física o material' no ha llegado a relacionarse nunca con los alimentos ni con los frutos inmaduros, de forma que no ha llegado a desplazarse, como muchos de sus sinónimos, hasta los contextos de mors immatura, ni en la literatura convencional ni en la poesía epigráfica.

\section{Grupo B.}

\subsection{IMMATVRVS.}

\subsubsection{El diccionario.}

El adjetivo immaturus, compuesto como lo era immitis, en este caso a partir de maturus ('que llega a su pleno desarrollo', incluso 'viejo', 'de edad'), se aplica, en su primera acepción ${ }^{26}$ a los frutos y plantas que aún no han madurado. En el mismo sentido se aplica también a personas o animales jóvenes y a hechos sucedidos antes de tiempo. Vemos, pues, que su significado, como en los casos anteriores, también se ha ido desplazando desde lo concreto hasta lo abstracto. Desde la información que nos proporcionan los diccionarios, es fácil deducir, como de hecho nos demostrarán los textos, que este adjetivo desarrolló una sola de las derivaciones metafóricas conocidas por acerbus e immitis, es decir, la relacionada con el paso del tiempo, muy cercana en este caso al significado originario de índole temporal del tema en

26 Cf. $O L D$, s.v.

EMERITA (EM) LXXIV 1, enero-junio 2006 pp. 113-144 ISSN 0013-6662 
$-u$ - *matu-, del que procede y que se reconoce también en palabras como matutinus, maturitas, etc. El hecho de que la raíz de este adjetivo esté tan fuertemente vinculada a una noción temporal originaria, facilitaría el desplazamiento de su significado desde los frutos (inmaduros) hasta los jóvenes (también inmaduros) y hasta la propia muerte, si ésta acaecía antes de lo previsto; pero impediría al mismo tiempo que se desarrollase esa otra derivación metafórica relacionada con la percepción sensorial, que había hecho que adjetivos (como acerbus o immitis) que tenían un significado originario relacionado con el sabor amargo de los frutos inmaduros llegasen a poder expresar también la amargura del alma.

\subsubsection{La literatura.}

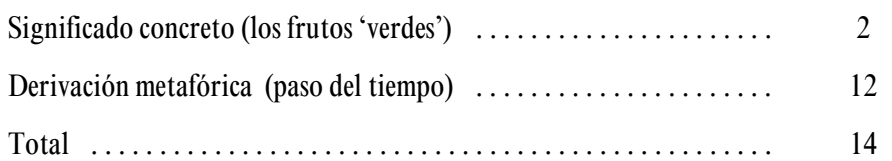

El número total de usos de este adjetivo vemos que desciende considerablemente respecto a acerbus o immitis. Escasos igualmente resultan los textos en que immaturus se usa con su primera acepción (Apul., Met. IX 35.13 y Sil. Ital., Pun. XV 533); significado que facilitó, también para este adjetivo, su uso 'metafórico' en otro campo significativo no tan concreto como el de los frutos, el de la duración de la vida del hombre. Pero los doce textos que desarrollan este último significado no son totalmente idénticos; cinco de ellos se refieren sencillamente a hechos sucedidos antes del tiempo previsto o a personas jóvenes, que aún no han madurado (Pl., Per.315, Mart. IX 7.5, Apul., Met. V 29.9, VIII 9.23 y XI 21.9); los restantes, sin embargo, se insertan en contextos de mors immatura (Lucr. V 221, Cat. 96.5, Verg., Aen. XI 166, Hor., S. II 8.59, Tib. II 6.29, Prop. III 7.3 y IV 11.17).

\subsubsection{La epigrafía.}

Es de esperar que, puesto que su significado está muy relacionado con contextos de mors immatura, sea éste un adjetivo muy usado en las inscripciones funerarias en verso, donde este tópico de la muerte prematura recibe un amplio y variado desarrollo literario. Nos encontramos, en efecto, con 38 ejemplos epigráficos ${ }^{27}$, todos ellos en inscripciones funerarias y con el mismo significado ('prematuro', 'antes del tiempo previsto'), y siempre con el mismo tipo de sustantivo (mors o similares). También aquí, como ya habíamos advertido para acerbus, encontramos en un par de textos el punto de partida, no cronológico pero sí conceptual de estos usos metafóricos. En ellos se ejemplifica la mors immatura, no mediante la metáfora sino recurriendo

27 Su uso es muy superior al que se hace de él en la literatura.

EMERITA (EM) LXXIV 1, enero-junio 2006 pp. 113-144 ISSN 0013-6662 
explícitamente al símil frutal: CLE 1543,3: sicut in arbore poma: inmatura cadunt et matura leguntur; CLE 465B,8: poma: [aut matar] a cadunt aut [inmatura] legun$t_{u}{ }^{28}$. Fuera ya del símil frutal explícito, los ejemplos restantes hacen un uso metafórico de este adjetivo en textos muy similares a los siguientes: CLE 167,2: mors inmatura fecit mater faceret filio; 995B,13: quodque mihi eripuit mors inmatura iuuentae. Se entiende, pues, que este adjetivo (y los dos que siguen) se hayan englobado en un grupo en cierta manera distinto al que pertenecen acerbus, immitis, etc., pues su significado originario no tiene relación con el sabor amargo de los frutos inmaduros y no es, de hecho, tan concreto. De ahí que no desarrolle esa derivación metafórica relacionada con la amargura no ya del fruto sino del alma.

\subsection{PRAEMATVRVS.}

\subsubsection{El diccionario.}

Igualmente compuesto a partir de maturus, también praematurus (que significa 'precoz', 'prematuro', 'temprano') se aplica principalmente a los frutos que aún no han madurado; y de ahí, por extensión, a todo lo que suceda o llegue antes de tiempo. Es, pues, de prever, que vayamos a encontrarlo también aplicado a la mors immatura y que muestre el mismo comportamiento que su 'sinónimo' immaturus estudiado supra.

\subsubsection{La literatura.}

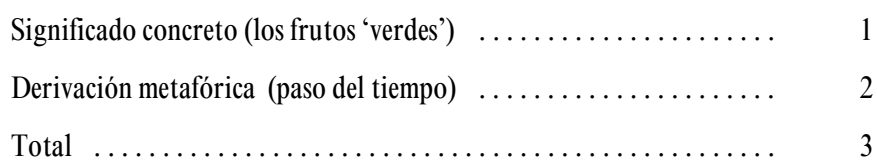

Si ya resultaba escaso el número de usos literarios de immaturus (14 ejemplos), el caso de praematurus apenas sí se usa en los autores seleccionados, de forma que muy pocas conclusiones se pueden extraer. En todo caso, la situación es muy similar en ambos casos. Un solo texto con el significado más concreto de 'fruto inmaduro' ${ }^{29}$ y en los otros dos con el más abstracto y relacionado con su significado temporal originario de 'prematuro' (Sil. Ital., Pun. XV 356 y Apul., Met. IX 23.11).

\subsubsection{La epigrafía.}

Tres también son los ejemplos de praematurus en la poesía epigráfica, si bien en uno de ellos se trata del adverbio praemature y no del adjetivo. Todos ellos apare-

28 Para el estudio detallado de los orígenes y expansión, literaria y epigráfica, de este símil frutal, cf. Fernández 2003, esp. pp. 327-328.

29 Apuleyo, Met. IX 33.26.

EMERITA (EM) LXXIV 1, enero-junio 2006 pp. 113-144 ISSN 0013-6662 
cen en inscripciones funerarias y en un indiscutible contexto de mors immatura (CLE 466,2; 1109,1 y 1301,4). Tampoco, como en immaturus, su significado originario tiene relación con el sabor amargo de los frutos inmaduros, ni ha desarrollado, por tanto, la derivación metafórica relacionada con la amargura del alma.

\subsection{PROPERATVS.}

\subsubsection{El diccionario.}

Adjetivo verbal de propero, tiene el significado único de 'presuroso, acelerado, rápido'; de manera que parece previsible que vayamos a encontrarlo también aplicado a la mors inmatura y que muestre un comportamiento similar al de sus 'sinónimos' immaturus o praematurus estudiados supra. Sin embargo, y a diferencia de lo que sucedía con sus mencionados sinónimos, properatus no tuvo en su origen ningún ámbito de aplicación concreto relacionado, por ejemplo, con los frutos que aún no han madurado; su única acepción es siempre abstracta y hace referencia al paso apresurado del tiempo, lo cual, como veremos, influirá en sus usos literarios y epigráficos.

\subsubsection{La literatura.}

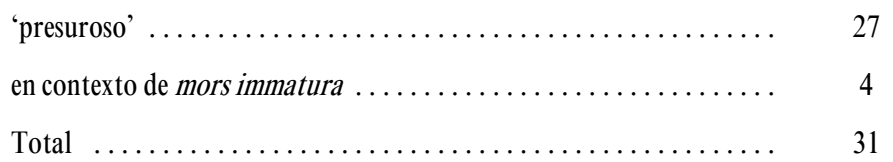

Si resultaba escaso el número de usos literarios de immaturus (14 ejemplos) y praematurus (sólo 3 ejemplos), los usos de properatus se ven algo acrecentados en los autores seleccionados, y con el significado mayoritario y fundamental de 'apresurado' o 'rápido', sin que apenas llegue a aplicarse a contextos de mors immatura. Con todas las precauciones a que el número escaso de ejemplos (sobre todo para los dos primeros) nos obliga, y dada la fuerte tendencia a la especialización en contextos de mors immatura que muestran los primeros frente al último, podríamos llegar a concluir que estos tres adjetivos se distribuyeron sus ámbitos de aplicación entre la mors inmatura (immaturus y praematurus) y la 'precipitación de algún hecho' (properatus).

\subsubsection{La epigrafía.}

Cuatro son los ejemplos de properatus en la poesía epigráfica, los cuales, frente a la situación descrita en el párrafo anterior, aparecen en un indiscutible contexto de mors immatura (CLE 1402,8: quem mihi tam subito mors properata tulit; 2005,2; 1260,3; y 1550,2). Properatus nos muestra, pues, en la poesía epigráfica, un uso idéntico al de sus 'sinónimos' immaturus y praematurus: el que se refiere, como hemos visto, a la muerte que llega antes de tiempo.

$$
\text { EMERITA (EM) LXXIV 1, enero-junio } 2006 \text { pp. 113-144 ISSN 0013-6662 }
$$




\section{CONCLUSIONES.}

Del estudio pormenorizado de estos dos grupos de adjetivos, relacionados con acerbus, bien desde su significado originario y concreto (el amargor de los frutos inmaduros), bien a través de algunas de sus dos derivaciones metafóricas (la que sirvió para describir sensaciones amargas o para designar la muerte anticipada), podemos extraer, además de las conclusiones globales, fácilmente previsibles desde la afinidad demostrada entre sus distintos campos significativos (concretos y/o metafóricos), una serie de conclusiones parciales que vale la pena destacar, a modo de recapitulación final.

5.1. Por lo que respecta al primero de los grupos (es decir, aquellos cuyo significado originario hace referencia a cualquier sensación concreta relacionada con los frutos inmaduros y pueden emplearse, en principio, además de con su significado concreto, con las dos derivaciones metafóricas conocidas), conviene insistir en que no todos ellos presentan el mismo grado de especialización epigráfica para contextos de mors immatura, y ahondar en las razones para una especialización total, parcial o nula.

5.1.1. Entre los adjetivos cuyo significado originario y concreto estaba relacionado con el sentido del gusto, con el sabor más o menos amargo o desagradable de los alimentos (immitis, amarus, acidus, acer, asper), se observa lo siguiente:

5.1.1.1. Existe una relación demostrable entre la disminución (o pérdida) del significado más concreto y originario de los adjetivos, y la mayor variedad y frecuencia de sus usos metafóricos. Es así como immitis, cuyo significado concreto en relación con la inmadurez de los frutos se ha perdido casi del todo en la literatura, desarrolló dos derivaciones metafóricas, la de los sentimientos amargos (ampliamente documentada en los textos literarios) y la de la muerte anticipada (apenas esbozada en la literatura y única en la poesía epigráfica); amarus, en cambio, que conservó en la literatura sus usos más concretos y literales, sólo llegó a establecer relaciones conceptuales con las sensaciones, mucho menos concretas, de amargura o crueldad, sin que se le conozca - ni en los textos literarios ni en los epigráficos - la segunda de las derivaciones metafóricas, que lo hubiera hecho apto para calificar a la mors immatura.

5.1.1.2. Algunos de estos adjetivos (acidus, acer, asper), pese a su relación con el sentido del 'gusto', no llegaron nunca a aplicarse al sabor de los frutos que no han madurado, especializándose más bien para alimentos de sabor penetrante, agrio, etc. Precisamente por ello, porque ninguno de ellos sirvió para calificar el

EMERITA (EM) LXXIV 1, enero-junio 2006 pp. 113-144 ISSN 0013-6662 
sabor de los frutos inmaduros, no llegaron a tener un ámbito de aplicación en contextos de mors immatura, ni en la literatura ni en la epigrafía, como hemos visto supra.

5.1.2. En un par de adjetivos, crudus y crudelis, su aplicación a los frutos 'verdes' no ha sido tan directa, sino procedente de su significado etimológico de 'sangrante', a partir del cual pudo aplicarse a los alimentos 'crudos', es decir, sin terminar de cocinar, y extenderse a los frutos 'verdes', es decir, sin terminar de madurar. Desde ahí, una derivación metafórica facilitó su uso para todo lo inacabado o inmaduro.

5.1.2.1. Crudus conoció además en la literatura una segunda derivación metafórica hacia significados mucho más abstractos relacionados con la 'crueldad'; un significado que pudo sobrevenirle desde su etimología 'sangrante', o incluso ¿por qué no?- desde su frecuente uso para los frutos verdes (por los mismos caminos conceptuales descritos ya para acerbus o immitis). Sea como fuere, también crudus, como acerbus o inmitis, muestra en la poesía epigráfica (aunque su baja frecuencia nos impida ser concluyentes) un uso especializado para la mors immatura.

5.1.2.2. El caso de crudelis, relacionado etimológicamente con crudus y, en consecuencia, con el mismo significado de 'sangrante', ha resultado especialmente interesante, pues su estudio detallado, en la literatura y en la epigrafía, nos ha llevado a proponer la ampliación de las acepciones que para el mismo admiten tradicionalmente los distintos diccionarios. Hemos podido ver, en efecto, que junto a su significado regular y mayoritario relacionado con la crueldad (¡único que recogen los diccionarios!), crudelis, además de conservar su sentido etimológico de 'sangrante' (que no registran los diccionarios) en un pequeño grupo de ejemplos literarios, ha llegado a usarse con la acepción de 'prematuro' en contextos de mors immatura, tras haber sufrido el mismo proceso de derivación metafórica que crudus o acerbus, a partir de su aplicación a los frutos que aún no han madurado. Pues bien, esta última acepción, casi desconocida -ipero no ausente!- en la literatura e ignorada por los diccionarios al uso, es la que prevalece -según hemos podido comprobar y demostrar- en la poesía epigráfica. Dicha especialización ha resultado fundamental a la hora de interpretar y traducir los textos epigráficos en los que se inserta crudelis y nos ha proporcionado claves definitivas para la comprensión de algunos pasajes oscuros.

5.1.3. Durus y rigidus, relacionados ambos con 'la dureza al tacto', desarrollaron de modo preferente en la literatura una derivación metafórica desde la que llegaron a expresar situaciones desagradables, adversas, crueles. Pero al mismo tiempo, muestran, en relación con la mors immatura, un comportamiento regulado fundamentalmente por su aplicación o no a los frutos inmaduros. 
5.1.3.1. Es así como durus, para el que detectábamos, ya en la literatura, un desplazamiento desde el ámbito del sentido del tacto al del gusto, se ha podido aplicar de hecho a los frutos que no han madurado en el árbol; lo cual lo convierte en 'sinónimo' de acerbus y facilita la derivación metafórica hacia la vida truncada antes de tiempo. Su uso epigráfico, como hemos visto, muestra, por una parte, el notable abandono de la derivación metafórica más frecuente en la literatura (la dureza de los sentimientos) y, por otra, una clara tendencia a la especialización para casos de mors immatura, similar a la que ya hemos descrito para crudelis.

5.1.3.2. Rigidus sin embargo, tal vez por el mayor peso de su significado más literal, pero sobre todo porque su 'dureza física o material' no llegó a relacionarse nunca con los alimentos en general ni con los frutos inmaduros en particular, no conoció -como muchos de sus sinónimos- el desplazamiento hasta los contextos de mors immatura, ni en la literatura de autores conocidos, ni en la poesía epigráfica.

5.2. Por lo que respecta al segundo grupo, es decir, a aquellos adjetivos que hacen referencia al paso del tiempo en relación con la madurez de los frutos (immaturus, praematurus), podemos deducir que su etimología, tan fuertemente vinculada a la noción temporal, condiciona su única derivación metafórica, desde el símil frutal, y facilita su especialización epigráfica para contextos de mors immatura. Especial resulta en este grupo el caso de properatus, pues, si bien nunca se relacionó con los frutos inmaduros, pudo especializarse en la poesía epigráfica para contextos de mors immatura por presión de sus 'sinónimos' immaturus y praematurus.

6. Los diversos autores considerados: su uso de toda la serie de adjetivos estudiados.

\begin{tabular}{|c|c|c|c|c|}
\hline & \multirow{2}{*}{$\begin{array}{c}\text { Significado } \\
\text { originario }\end{array}$} & \multicolumn{2}{|c|}{ Derivaciones metafóricas } & \multirow{2}{*}{ Totales } \\
\hline & & 1 sensaciones & 2 paso del tiempo & \\
\hline \multicolumn{5}{|l|}{ Plauto } \\
\hline amarus & 2 & 5 & - & 7 \\
\hline acer & - & 6 & - & 6 \\
\hline asper & 2 & - & - & 2 \\
\hline crudus & 3 & 2 & - & 5 \\
\hline durus & 2 & 7 & - & 9 \\
\hline immaturus & - & - & 1 & 1 \\
\hline \multicolumn{5}{|l|}{ LUCRECIO } \\
\hline amarus & 7 & 2 & - & 9 \\
\hline acidus & 1 & - & - & 1 \\
\hline
\end{tabular}

EMERITA (EM) LXXIV 1, enero-junio 2006 pp. 113-144 ISSN 0013-6662 


\begin{tabular}{lcccc} 
& $\begin{array}{r}\text { Significado } \\
\text { originario }\end{array}$ & \multicolumn{2}{c}{ Derivaciones metafóricas } & 1 sensaciones \\
\cline { 2 - 5 } & 19 & 26 & - & 2 paso del tiempo \\
acer & 2 & 13 & - & 45 \\
asper & - & 1 & - & 15 \\
crudelis & 4 & 9 & - & 13 \\
durus & 4 & - & - & 4 \\
rigidus & - & - & 1 & 1 \\
immaturus & & &
\end{tabular}

\section{Catulo}

$\begin{array}{lcccc}\text { immitis } & - & 2 & i 1 ? & 3 \\ \text { amarus } & 1 & - & - & 1 \\ \text { acer } & 1 & - & - & 1 \\ \text { acidus } & 1 & 2 & - & 3 \\ \text { crudelis } & - & 7 & - & 7 \\ \text { asper } & 2 & 13 & - & 15 \\ \text { durus } & 3 & 2 & - & 5 \\ \text { rigidus } & 1 & - & - & 1 \\ \text { immaturus } & - & - & 1 & 1\end{array}$

VIRGILIO

$\begin{array}{lcccc}\text { immitis } & - & 4 & - & 4 \\ \text { amarus } & 12 & 6 & - & 18 \\ \text { acidus } & 1 & - & - & 1 \\ \text { acer } & 4 & 52 & - & 56 \\ \text { asper } & 15 & 26 & - & 41 \\ \text { crudus } & 6 & - & 1 & 7 \\ \text { crudelis } & 4 & 26 & 9 & 39 \\ \text { durus } & 31 & 53 & 5 & 89 \\ \text { rigidus } & 6 & - & - & 6 \\ \text { immaturus } & - & - & 1 & 1 \\ \text { properatus } & 1 & - & - & 1\end{array}$

HORACIO

$\begin{array}{lcccc}\text { immitis } & 1 & 2 & - & 3 \\ \text { amarus } & 2 & 4 & - & 6 \\ \text { acidus } & 1 & 1 & - & 2 \\ \text { acer } & 8 & 31 & - & 39 \\ \text { asper } & 2 & 16 & - & 18 \\ \text { crudus } & 2 & - & 2 & 4 \\ \text { crudelis } & - & 3 & - & 3 \\ \text { durus } & 7 & 32 & - & 39 \\ \text { rigidus } & 1 & 4 & - & 5\end{array}$

EMERITA (EM) LXXIV 1, enero-junio 2006 pp. 113-144 ISSN 0013-6662 
LOS ADJETIVOS LATINOS RELACIONADOS CON ACERBVS ...

\begin{tabular}{lcccc} 
& $\begin{array}{r}\text { Significado } \\
\text { originario }\end{array}$ & 1 sensaciones & 2 paso del tiempo & Totales \\
${$\cline { 2 - 4 }$} }$ & - & - & 1 & 1
\end{tabular}

TIBULO

$\begin{array}{lcccc}\text { immitis } & - & 3 & 1 & 4 \\ \text { amarus } & - & 2 & - & 2 \\ \text { acer } & 1 & 2 & - & 3 \\ \text { asper } & 1 & 7 & - & 8 \\ \text { crudelis } & - & 3 & - & 3 \\ \text { durus } & 9 & 13 & - & 22 \\ \text { rigidus } & 1 & - & - & 1 \\ \text { immaturus } & - & - & 1 & 1\end{array}$

PROPERCIO

amarus

acer

asper

crudelis

durus

immaturus

12

-
1
-
-
-
12
-

\section{1}

10

2

3

7

40

$-$

4

3

22

1

OVIDIO

$\begin{array}{lcccc}\text { immitis } & - & 23 & - & 23 \\ \text { amarus } & 12 & 14 & - & 26 \\ \text { acer } & 3 & 24 & - & 27 \\ \text { asper } & 15 & 18 & - & 33 \\ \text { crudus } & 3 & 6 & - & 9 \\ \text { crudelis } & 3 & 38 & - & 41 \\ \text { durus } & 100 & 105 & - & 205 \\ \text { rigidus } & 31 & 24 & - & 55 \\ \text { properatus } & 11 & - & 3 & 14\end{array}$

MARCIAL

$\begin{array}{lcccc}\text { amarus } & 2 & 3 & - & 5 \\ \text { acidus } & 1 & - & - & 1 \\ \text { acer } & 1 & 7 & - & 8 \\ \text { asper } & 3 & 5 & - & 8 \\ \text { crudus } & 6 & - & 4 & 10 \\ \text { crudelis } & - & 7 & 2 & 9 \\ \text { durus } & 7 & 24 & 1 & 32 \\ \text { rigidus } & 6 & 7 & - & 13\end{array}$

EMERITA (EM) LXXIV 1, enero-junio 2006 pp. 113-144 ISSN 0013-6662 


\begin{tabular}{|c|c|c|c|c|}
\hline & & Derivacio & s metafóricas & \\
\hline & originario & 1 sensaciones & 2 paso del tiempo & Totales \\
\hline immaturus & - & - & 1 & 1 \\
\hline properatus & 1 & - & - & 1 \\
\hline APULEYO & & & & \\
\hline amarus & 2 & 2 & - & 4 \\
\hline acidus & - & 1 & - & 1 \\
\hline acer & 1 & 4 & - & 5 \\
\hline asper & 5 & 5 & - & 10 \\
\hline crudus & 4 & 1 & - & 5 \\
\hline crudelis & - & 5 & - & 5 \\
\hline durus & 1 & 4 & - & 5 \\
\hline immaturus & 1 & - & 3 & 4 \\
\hline praematurus & 1 & - & 1 & 2 \\
\hline Silio ITÁLICO & & & & \\
\hline immitis & - & 20 & - & 20 \\
\hline acer & 2 & 35 & - & 37 \\
\hline asper & 1 & 40 & - & 41 \\
\hline crudus & - & 14 & 2 & 16 \\
\hline crudelis & - & 3 & - & 3 \\
\hline durus & 16 & 48 & - & 64 \\
\hline rigidus & 2 & 2 & - & 4 \\
\hline immaturus & 1 & - & - & 1 \\
\hline praematurus & - & - & 1 & 1 \\
\hline properatus & 10 & - & 1 & 11 \\
\hline ESTACIO & & & & \\
\hline immitis & - & 15 & ¿1? & 16 \\
\hline amarus & 3 & 1 & 4 & 8 \\
\hline acer & 2 & 11 & - & 13 \\
\hline asper & 10 & 45 & - & 55 \\
\hline crudus & - & 14 & 5 & 19 \\
\hline crudelis & - & 28 & - & 28 \\
\hline durus & 15 & 64 & 3 & 82 \\
\hline rigidus & 6 & 2 & - & 8 \\
\hline
\end{tabular}

7. Recapitulación final y propuestas de traducción.

7.1. Las conclusiones extraídas en su momento del estudio del adjetivo acerbus y su especialización epigráfica para la mors immatura, resultan 
igualmente válidas para el conjunto de adjetivos estudiados a los largo de estas páginas. Así, desde una realidad tangible y cercana a nuestra experiencia ('los frutos inmaduros son amargos'), hemos llegado a la comprensión de otras dos realidades no tan concretas ni fáciles de entender: la amargura del alma y la duración de la vida del hombre. De manera que el campo semántico de estos adjetivos se ha ido configurando en torno a una, otra o ambas derivaciones metafóricas, regulándose dicha configuración según la mayor o menor presencia de sus acepciones más concretas, y de acuerdo a su aplicación o no a contextos de mors immatura.

7.2. Por último, y puesto que el estudio de esta serie de adjetivos desde la perspectiva de la TCM, resulta de gran utilidad de cara a la interpretación (y, por tanto, traducción) exacta, desde el punto de vista semántico, de todas sus acepciones (la literal y originaria, la metafórica de la percepción sensorial y la metafórica relacionada con el paso del tiempo), ofrecemos, a modo orientativo, una propuesta de traducción para cada una de las acepciones:

\begin{tabular}{lccc} 
& Significado literal & Derivación metafórica 1 & Derivación metafórica 2 \\
\cline { 2 - 4 } acerbus & amargo & amargo & prematuro \\
immitis & fuerte & severo & prematuro \\
amarus & amargo & amargo & - \\
acidus & penetrante & penetrante & - \\
acer & agrio & exacerbado & - \\
asper & áspero & exasperado & - \\
crudus & sangrante/inmaduro & cruento & prematuro \\
crudelis & sangrante & cruento & prematuro \\
durus & duro & duro & prematuro \\
rigidus & rígido & inflexible & - \\
immaturus & inmaduro & - & prematuro \\
praematurus & prematuro & - & prematuro \\
properatus & apresurado & - & prematuro
\end{tabular}


REFERENCIAS BIBLIOGRÁFICAS.

Chevallier, R., Épigraphie et Littérature à Rome, Faenza, 1972.

$C L E=$ F. Bücheler-E. Lommatzsch, Carmina Latina Epigraphica, Leipzig 1897-1926.

Cugusi, P., Aspetti letterari dei CLE, Bologna $1996^{2}$.

Fauconnier, G., Mental spaces, New York 1994.

Fauconnier, G. \& Turner, M., Conceptual projection and middle spaces, UCSD (Department of Cognitive Science Technical Report 9401), 1994. URL: http://cogsci.ucsd.edu; http://www.wam.umd.edu.

Fernández Martínez, C., Poesía Epigráfica Latina (II vols.), Madrid, 1998-99.

Fernández Martínez, C., «Acerbus. la amargura de morir antes de tiempo», EMERITA 71,2, 2003, pp. 313337.

Gibbs, R.W., The Poetics of Mind, Cambridge, 1944.

Gómez Pallarès, J., «Otros ecos en la Eneida de Virgilio: la 'evidencia' de los CLE», Helmantica 1993, pp. 267-280.

Grady, J.E., Oakley, T. \& Coulson, S., Blending and Metaphor, in: Gibbs, R. \& Stehen, G. (Eds.), Metaphor in cognitive linguistics. (Selected papers from the Fifth International Cognitive Linguistics Conference), Amsterdam, 1999, pp. 101-124.

Hernández, R., Poesía latina sepulcral de la Hispania Romana: estudio de los tópicos y sus formulaciones, Valencia, 2001.

Lakoff, G. \& Johnson, M., Metaphors we live by, Chicago 1980.

Id., Metáforas de la vida cotidiana (Traducción e introducción de J. A. Millán y S. Narotzky), Madrid, 1991.

Lier, B., «Topica Carminum Sepulcralium Latinorum», Philologus 1903, pp. 445-447; pp. 653-603; 1904, pp. 54-65.

Martínez Vázquez, R., «The cognitive base of case syncretism: Conceptual blending of instrumental, comitative, and agent in ancient Greek», Sprachtypol. Univ. Forsch. (STUF), Berlin 54, 2001, pp. 329-345.

Id., «Metáfora oracional: incidencia en la estructura pragmática de la oración», en Gramática contrastiva inglés-español(ed. M. Martínez Vázquez), Huelva, 1995, pp. 77-111.

Martínez, R., Ruiz, E., \& Fernández, R., Gramática funcional-cognitiva del griego antiguo I. Sintaxis y semántica de la predicación, Sevilla, 1999.

Nerlich, B., «Semantic Development and Semantic Change, with special reference to metaphor and metonymy (An overview of theories from 1950 to 1990)», http://www.le.ac.uk/psycology/metaphor/ semdev.html.

Ricci, M.L., Carletti Colafrancesco, P.C. \& Gamberale, L., «Motivi dell'oltretomba virgiliano nei CLE», Atti del Convegno Virg. Dei Brindisi nel Bimill. della morte, Brindisi, 1983, pp. 199-234.

Con arreglo a las normas editoriales vigentes para las publicaciones periódicas del CSIC, se hace constar que el original definitivo de este artículo se recibió en la redacción de EMERITA en el segundo semestre de 2005, siendo aprobada su publicación en ese mismo período (30.9.05 - 11.12.05)

EMERITA (EM) LXXIV 1, enero-junio 2006 pp. 113-144 ISSN 0013-6662 